\title{
Earmarking tobacco taxes for health purposes via median entities
}

\section{Michael Igoumenidis*, Kostas Athanasakis}

\author{
*Correspondence to: Michael Igoumenidis, Email: migoumen@ppp.uoa.gr \\ Copyright: ( 2014 by Kerman University of Medical Sciences \\ Citation: Igoumenidis M, Athanasakis K. Earmarking tobacco taxes for \\ health purposes via median entities. Int J Health Policy Manag 2014; 3: 159. \\ doi: $10.15171 /$ ijhpm. 2014.72 \\ Received: 14 August 2014, Accepted: 20 August 2014, ePublished: 20 August 2014
}

iscal policies are an especially promising lever for reducing the burden of non-communicable diseases and injuries (1). On World No Tobacco Day 2014, World Health Organization (WHO) repeated with greater intensity its well-known proposal (2) on raising tobacco taxes to encourage users to stop or reduce consumption, and to prevent potential users from taking up smoking. Evidence as to why this is an effective strategy abounds (3). Despite concerns over manufacturers' political influence, technical problems such as tax manipulation, and increased smuggling considerations, it is hoped that governments shall be scaling their efforts toward this direction in the next few years, by enforcing increases in specific excise taxes. A 2011 review of more than 100 econometric studies estimates that doubling inflation-adjusted prices should reduce consumption by about one third (4). In terms of revenue, WHO estimates that raising specific excise taxes on tobacco to double prices would raise about 100 billion US dollars per year worldwide, in addition to the approximately 300 billion US dollars that governments already collect on tobacco (5). Each country enforcing such taxes must decide how to allocate their share of this prospective additional revenue in advance. Careful consideration is particularly important; this is a chance for tobacco to atone, partly at least, for the damage it has inflicted throughout the years of its uncontrollable use.

The process of earmarking (or dedicating) revenues from tobacco taxes for health purposes constitutes a fairly recent policy, adopted in various forms globally. Experience demonstrates that public support for higher tobacco taxes is greater when some of the increased revenues are used to support health-focused programmes (6). Rather than paying without knowing where the money is used, earmarked taxes assure taxpayers that these revenues are targeted to specific desirable purposes, regardless of the fiscal authority's mandate to allocate budgets as they see appropriate. However, economists argue that policy-makers have the opportunity to use these funds in an indirect way, in the sense that fiscal authorities can decrease general-fund spending on targeted expenditures (7). This is especially tempting in conditions of fiscal austerity, particularly for middle- and low-income countries with small budgets and pressing needs. A better, more secure way to benefit health from tobacco taxes has to be found.

The solution might lie in median autonomous or semi- autonomous entities, as is the case in several countries. For instance, Thailand's Thai Health Promotion Foundation receives $2 \%$ of the total national tax revenue on alcohol and tobacco products, and supports groups and organizations that are already working on public health issues. Such a foundation could also accept applications to fund healthcare research projects, thus enhancing a country's scientific capabilities. Its public autonomous status would allow partnerships in both public and private sectors. The foundation would have to report directly to a higher authority, but in essence it would be independent from ministries of finance. Thus its resources would be protected, and smokers would know that their increased taxes are allocated directly to health-focused programmes.

Countries differ in their needs, abilities, and priorities. There is no universal approach to the most efficient use of tobacco tax money, but earmarking it to health-focused programmes via an autonomous foundation offers important advantages. Policy-makers who will respond to WHO's call need to research this and other options thoroughly in order to benefit as much as possible from raising taxes on tobacco.

\section{Ethical issues \\ Not applicable.}

\section{Competing interests}

Authors declare that they have no competing interests.

\section{Authors' contributions}

Both authors contributed to forming the viewpoint which is expressed in this letter. MI drafted the manuscript; KA reviewed and revised the manuscript. Both authors approved the final version

\section{References}

1. Jamison DT, Summers LH, Alleyne G, Arrow KJ, Berkley S, Binaqwaho A, et al. Global health 2035: a world converging within a generation. Lancet 2013; 382: 1898-955. doi: 10.1016/ s0140-6736(13)62105-4

2. WHO Framework Convention on Tobacco Control, 2003: article 6 [internet]. [cited 2014 August]. Available from: http://whqlibdoc. who.int/publications/2003/9241591013.pdf?ua=1

3. Chaloupka FJ, Yurekli A, Fong GT. Tobacco taxes as a tobacco control strategy. Tob Control 2012; 21: 172-80. doi: 10.1136/ tobaccocontrol-2011-050417

4. International Agency for Research on Cancer (IARC). Effectiveness of tax and price policies for tobacco control: IARC handbook of cancer prevention, vol. 14. Lyon: IARC; 2011.

5. World Health Organization (WHO). WHO report on the global tobacco epidemic, 2013: enforcing bans on tobacco advertising, promotion and sponsorship. Geneva: WHO; 2013.

6. WHO Technical Manual on Tobacco Tax Administration 2011 [internet]. [cited 2014 August]. Available from: http://whqlibdoc. who.int/publications/2010/9789241563994_eng.pdf

7. Crowley GR, Hoffer AJ. The effects of dedicating tax revenues. Mercatus on Policy 109, June 2012 [internet]. [cited 2014 August]. Available from: http://mercatus.org/sites/default/files/ The-Effects-Dedicating-Tax-Revenues-Crowley-Hoffer.pdf 